\title{
Positive Health Impact of Bad News: A Group Study at Tagad District
}

\author{
Terdsak Detkong, Radtada Kornprasi \\ Ministry of Public Health, Nonthaburi, Thailand
}

\begin{abstract}
DM (diabetic mellitus) is a chronic disease that leads to problems and complications. There are many people with minimal abnormal FPG (Fasting Plasma Glucose) that will suffer from DM in long run. But, if they change some health behaviors, they will be healthy and not get DM too soon. Health behavior camp is a way to improve health behavior and this is a part of study on a diabetic camp at Tagad District. This paper aims to find out the reason of having better FPG in pre-DM participants. People who classified as risk group who have minimal abnormal FPG were divided into experiment group that will join the health behavior camp and control group. The 25 participants in control group were FPG-tested, as the 44 participant in experiment group took two months before camp began, the day camp begin and after camp. The data were analyzed with SPSS for Windows 11.5 program using $T$-test. Then the focus groups were designed to explain the finding. There was surprising data. The control group has improved health behavior, even they did not participate in diabetic camp, and there were 18 of 25 participants that changed health behavior until we found that they have normal FPG. This improvement is even better than that in experiment group which only 13 of 44 participants changed their FPG to normal range. This different is statistically significant $(p<0.05)$. Qualitative data from the focus groups show that motivation is the key factor of behavioral change. It seems to be that bad news (They have abnormal blood sugar and should join the diabetic camp but still no seat for them) can motivate behavioral change if introduced with some techniques, called brief advice.
\end{abstract}

Keywords: health behavior, Pre-DM (diabetic mellitus), brief advice

\section{Introduction}

DM (diabetic mellitus) is a chronic disease that brings patient many complications and costs them large amount of money to treat it. Diabetic patients should get treatment and change some behaviors. There are people who have minimal abnormal blood sugar. We call Pre-DM, because it will become true DM in long run. So, if we can make them change health behavior, this will give much benefit for individual and health system. Changing health behaviors are not easy but possible. There are many theories that guild us to motivate patients, especially stage of change (Prochaska \& DiClemente, 1983) and health believe model (Becker, 1974; 1984). We should help Pre-DM aware of problem and suffering if they become true DM and have enough motivation to change health behavior.

There are many interventions that can make behavior change, such as individual counseling group motivation health behavior camp. 


\section{Objective}

This study has prior objective to find out that motivation camp can bring people change health behavior. But, when we found that the data are strange, we came back to do focus groups.

The purpose now is to find reason to explain why people who did not participate in the camp had better blood sugar test.

\section{Participant Criteria}

The criteria are mainly as follows:

(1) People live in Tagad district lampoon province;

(2) They have minimal abnormal FPG (Fasting Plasma Glucose) (FPG = 101-119 mg \%);

(3) Volunteer to join the study.

There were 69 participants (44 for experiment and 25 for control).

\section{Method and Measurement}

The method and measurement are as follows:

(1) Collects FPG level before camp and one month after camp;

(2) The experiment group participate activity in camp (see Figures 1a and 1b);

(3) Process data analysis with SPSS Program;

(4) Focus groups (experiment and control group).

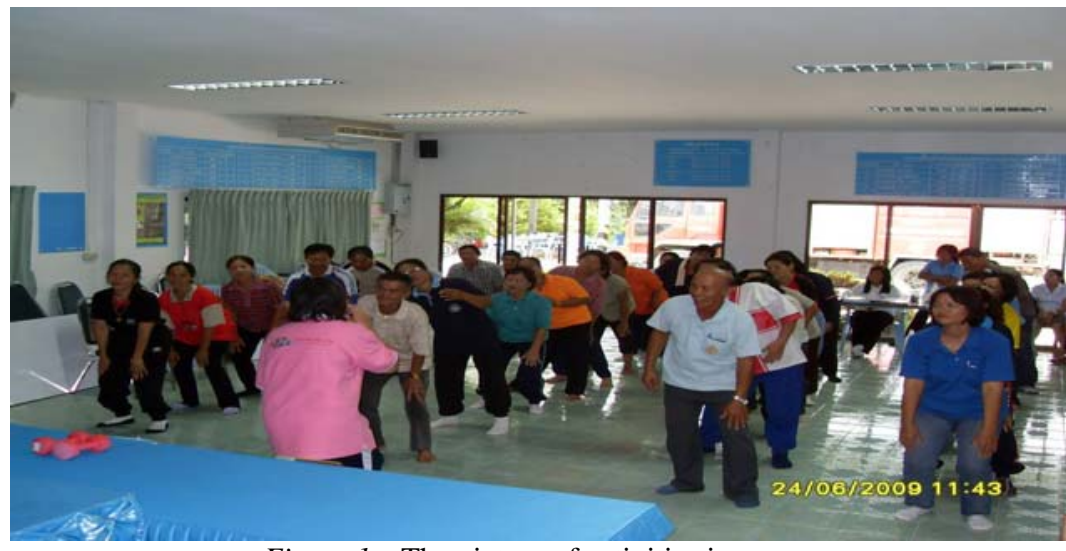

Figure 1a. The picture of activities in camp.

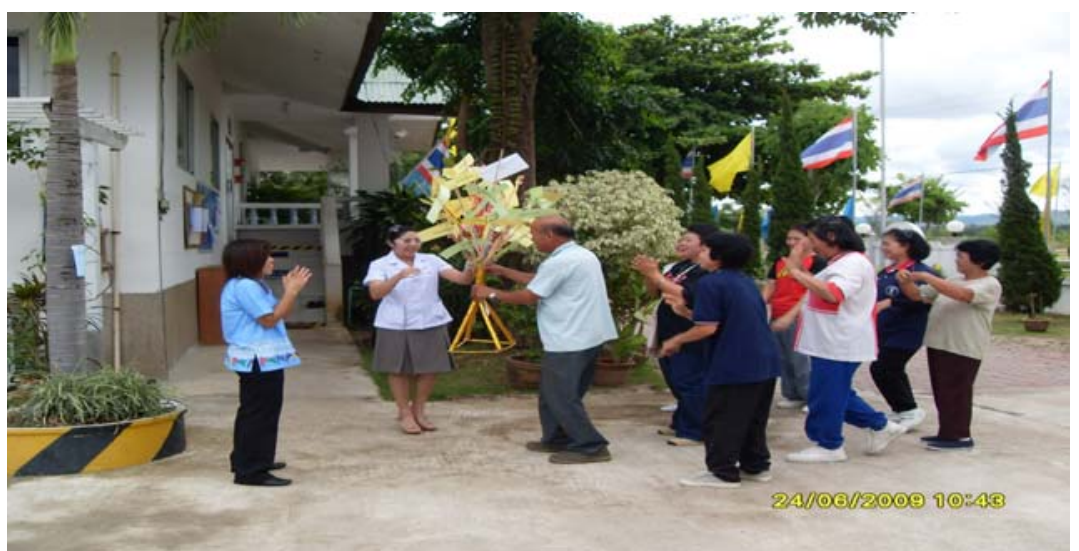

Figure $1 b$. The picture of activities in camp. 


\section{Result}

\section{Result of FPG}

Before the study began, there were some differences between experiment group and control group about blood sugar level, but not statistically significant (see Table 1). Pre-test of control group and experimental group had the average scores of FPG.

Table 1

Comparison of Pre-test Due Group Experimental and Group Control

\begin{tabular}{|c|c|c|c|c|c|c|}
\hline \multirow[b]{2}{*}{ Variable } & \multicolumn{2}{|c|}{ Group experimental } & \multicolumn{2}{|c|}{ Group control } & \multirow[b]{2}{*}{$T$-value } & \multirow[b]{2}{*}{ Two-tail sig. } \\
\hline & Mean & $\begin{array}{l}\text { Standard } \\
\text { deviation }\end{array}$ & Mean & $\begin{array}{l}\text { Standard } \\
\text { deviation }\end{array}$ & & \\
\hline FPG & 113.93 & 13.400 & 109.40 & 12.910 & 1.363 & 0.176 \\
\hline
\end{tabular}

After the study, the experiment group has improved FPG and 31\% of them returned to normal range. This improvement is statistically significant (see Table 2).

Table 2

Comparison of Pre- or Pose- test, Experimental Group $(n=44)$

\begin{tabular}{llllllll}
\hline \multirow{2}{*}{ Variable } & \multicolumn{3}{c}{ Pre } & & \multicolumn{2}{c}{ Post } & \\
\cline { 2 - 3 } & Mean & $\begin{array}{l}\text { Standard } \\
\text { deviation }\end{array}$ & & Mean & $\begin{array}{l}\text { Standard } \\
\text { deviation }\end{array}$ & T-value & Two-tail sig. \\
\hline FPG & 113.93 & 13.400 & 106.68 & 15.115 & 2.459 & 0.018 \\
\hline
\end{tabular}

Experimental group, post experiment and the experiment group had the average scores of FPG lower than that before experiment at the significance level 0.05 .

After the study, the control group has improved FPG and 72\% of them returned to normal range. This is statistically significant (see Table 3).

Table 3

Comparison of Pre-or Post- Test, Control Group $(n=25)$

\begin{tabular}{llllllll}
\hline \multirow{2}{*}{ Variable } & \multicolumn{3}{c}{ pre } & & \multicolumn{2}{c}{ Post } & \\
\cline { 2 - 3 } & Mean & $\begin{array}{l}\text { Standard } \\
\text { deviation }\end{array}$ & Mean & $\begin{array}{l}\text { Standard } \\
\text { deviation }\end{array}$ & T-value & Two-tail sig. \\
\hline FPG & 109.40 & 12.910 & 97.72 & 11.021 & 4.092 & 0.000 \\
\hline
\end{tabular}

Control group, post experiment and the control group had the average scores of FPG lower than that before experiment at the significance level 0.05 .

Data of FPG of control group are better than data from experiment group and statistically significant (see Table 4).

Table 4

Comparison of Post-test Due Group Experimental and Group Control

\begin{tabular}{|c|c|c|c|c|c|c|}
\hline \multirow[b]{2}{*}{ Variable } & \multicolumn{2}{|c|}{ Group experimental } & \multicolumn{2}{|c|}{ Group control } & \multirow[b]{2}{*}{$T$-value } & \multirow[b]{2}{*}{ Two-tail sig. } \\
\hline & Mean & $\begin{array}{l}\text { Standard } \\
\text { deviation }\end{array}$ & Mean & $\begin{array}{l}\text { Standard } \\
\text { deviation }\end{array}$ & & \\
\hline FPG & 106.68 & 15.115 & 97.72 & 11.021 & 2.595 & 0.012 \\
\hline
\end{tabular}

Post-test of control group had the average scores of FPG better than that experimental group at the 
significance level of 0.05 .

Because of abnormal finding, the group's focus was designed to find out the factors that caused this finding.

\section{Result of Focus Group}

In experiment group, participants were told about minimal abnormal FPG and offered to join in two days camp. They feel they are lucky and should wait for attending camp. Knowledge and practice to care themselves and prevent them from getting DM will be received during the staying in the camp.

The health personnel tend to tell fewer things about self-care, because they think everything necessary will be available in the camp.

After knowing that they (experiment group) will join the camp and can learn some important things about caring oneself, they tend to do fewer things for themselves, for example, exercise less and eat more. These events last for two to four weeks. Fortunately after joining the camp, they improve health behavior, some people improve health behavior more, but some people just as good as earlier.

This is the reason why some people improve their FPG after camp and some are not.

In the control group, they know their FPG. After health personnel inform that result, they inform them the blood test result and give some information including how to take care themselves and how to use exercise and diet as a way to improve FPG.

Health personnel told them the risk if they still do as they do before. Now, they are at risk, and if, do nothing, they will be fully diabetic in the future. With diabetic they would have taken, drugs may be insulin injection. In the future, other bad things, complications, such as chronic wound, infection, amputation, cataract, etc. will happen. During the interview, the control group said that, for their being, given insulin injection is the most suffering they do not want to have. For amputation, they do not fear because it is too far from here.

Health personnel spend more time in this control group, they think they must give enough information because they will not join the camp.

After knowing that information, people in control group have gone home with some feeling and idea. They must help themselves and they cannot wait for the next camp. Most of them began to do exercise, some plan for diet. This leads to new level of FPG.

It seems to be that people in risk group can take care themselves if they receive necessary information including knowledge and some bad news to build up optimal stress that finally transform to their motivation.

\section{Discussion}

People will change health behavior if they believe it is necessary. Although health information is important, having health behavior is one step after that. In this case, the health believes that model (Becker, 1974; 1984) has its role. If people perceived their threat and perceived benefit of changing health behavior know their barriers and plans for actions, they will start having new health behaviors (Rosenstock, Strecher, \& Becker, 1988; 1994).

Risk people should know that they are at risk which is so dangerous and that how to lower the risk and have chance to try doing it.

In this experiment, the health personnel done for the control group is something like "brief advice" which is a method of conversation (or interview). That used to promote health behavior change, such as drinking 
alcohol, smoking (Christian Mayer, 2008), exercise, drug adherence, etc.. The structures of brief advice are:

(1) Building relationship, even small due to limitation of time;

(2) Informing the over looks problem or risk that is so important. This information makes optimal stress and promotes motivation to change one's health behavior;

(3) Giving the way how to lower (or get rid of) the risk.

Brief advice is very important, because it usually takes only five to ten minutes but can motivate some people who are at risk.

\section{Conclusions}

Sometimes, bad news is beneficial if given in an appropriate way. This bad news about personal risk that is very important and no one could not look over. This bad news creates optimal stress and prepares people into "ready to change" stage. After that, giving information about the way to fix it must be followed. People in "ready to change" stage will get information and apply it into one's new health behavior.

\section{References}

Becker, M. H. (1974). The health belief model and personal health behavior. Health Education Monographs, 2, 324-473.

Meyer, C., Ulbricht, S, ... Baumeister, S. E. (2008). Proactive intervention for smoking cessation in general medical practice. Addiction, 103(2), 294-304.

Janz, N. K., \& Becker, M. H. (1984). The health belief model: A decade later. Health Education Quarterly, 11(1), 1-47.

Prochaska, J., \& DiClemente, C. (1983). Stages and processes of self-change of smoking: Towards an integrated model of change. Journal of Consulting and Clinical Psychology, 51, 390-395.

Rosenstock, I. M., Stretcher, V. J., \& Becker, M. H. (1988). Social learning theory and the health belief model. Health Education Quarterly, 15(2), 175-183.

Rosenstock, I. M., Stretcher, V. J., \& Becker, M. H. (1994). The health belief model and HIV risk behavior change (pp. 5-24). New York: Plenum Press. 